\section{EGF et spermatogenèse}

La spermatogenèse chez la souris se fait en trois stades : une phase mitotique de 8 jours, au cours de laquelle les spermatogonies se divisent pour donner les spermatocytes; ceux-ci, dans une deuxième phase de 13 jours, donnent naissance aux spermatides qui se transforment en spermatozoïdes dans une troisième phase de 13 ou 14 jours. Partant du fait que la glande sousmaxillaire, source principale du facteur de croissance $E G F$ (epidermal growth factor) en contient dix fois plus chez le mâle que chez la femelle, Tsutsumi et al. (NIH, Bethesda) ont examiné les effets de son ablation chez la souris C3H [1]. Au bout de trois à quatre semaines, l'EGF plasmatique devient indosable. En même temps la concentration en spermatozoïdes et en spermatides de l'épididyme tombe à moins de $50 \%$ du niveau antérieur, alors que celle de leurs précurseurs, les spermatocytes, augmente de $20 \%$. Ces altérations sont empêchées ou réversées par l'administration quotidienne de 5 microgrammes d'EGF. Ce sont donc les stades les plus matures qui réclament la présence de l'EGF. Le mécanisme d'action du facteur est encore hypothétique; ses propriétés mitogènes suggèrent qu'il pourrait stimuler directement la méiose des spermatocytes.

Ces observations faites in vivo sont d'un grand intérêt, car si on connaît les fonctions que l'EGF e. rce sur les cellules en culture, aucun rôle physiologique ne lui a encore été attribué. Dans le cas de la spermatogenèse, il ne saurait naturellement être seul en cause, puisque celle-ci a lieu en son absence, bien qu'à un rythme ralenti. Cependant, pour la fertilité masculine, l'importance de la concentration en spermatozoïdes permet de se demander si un déficit en EGF pourrait être responsable de certaines stérilités masculines, liées à une oligozoospermie.

J.-C.D.

1. Tsutsumi O, Kurashi H, Oka T. A physiological role of epidermal growth factor in male reproductive function. Science $1986 ; 233$ : 975-7.

\title{
BRÈVES
}

- Traitement des grands prématurés par le surfactant. Une des causes essentielles de la mort du très jeune prématuré est l'immaturité de la paroi alvéolaire du poumon. Une couche, le surfactant, contient des lipides en proportions définies, différentes chez le prématuré et l'enfant à terme. Le traitement par le surfactant, jadis inefficace, a fait récemment des progrès décisifs. D'après une équipe américanofinlandaise, la mortalité chez un groupe de nouveau-nés (938 g en moyenne), traités par du surfactant humain provenant de liquide amniotique et administré par voie intratrachéale, a été de $16 \%$ contre $52 \%$ chez des témoins de poids comparable. Ces résultats paraissent très encourageants.

[Merritt TA et al. $N$ Engl J Med 1986 ; 315 : 785-90.]

\section{Transfert de gènes d'hémoglobine chez la souris thalassémique}

Il existe un modèle murin de $B$ thalassémie dans lequel les animaux homozygotes pour la tare ne possèdent que les gènes $" B$ mineurs" et aucun gène " $B$ majeur ". La symptomatologie est celle d'une thalassémie humaine de gravité intermédiaire.

Le transfert de gène de $B$ globine humaine ou murine (gène $B$ majeur) dans l'ovocyte fécondé permet dans deux cas sur cent d'obtenir des animaux transgéniques possédant et exprimant le gène transféré (ou "transgène ") de manière héréditaire $[1,2]$. Des croisements ultérieurs entre souris transgéniques aboutissent dans la descendance à des animaux homozygotes pour le transgène... ou plutôt les transgènes car, dans $m / s n^{\circ} 1$ ool. 3, janvier 87 tous les cas, ces souris ont intégré de 50 à 100 copies du gène $B$ injecté. Ces souris homozygotes ont une correction totale de la symptomatologie thalassémique et, lorsque le gène $B$ transféré était d'origine humaine $\left(B^{\mathrm{h}}\right)$, synthétisent une grande quantité d'une hémoglobine hybride de formule $\alpha_{2}{ }^{\text {souris }} \beta_{2}{ }_{2}$. Comme nous l'avons indiqué dans le lexique $n^{\circ} 10$, vol. 2, une telle stratégie est totalement inapplicable au traitement des thalassémies humaines. Ces résultats démontrent cependant que la correction d'une thalassémie par le transfert de multiples gènes de globine, intégrés selon toute évidence hors de leur localisation normale, est possible. Selon la même méthode, il devrait en outre être possible de transférer des gènes humains modifiés par une mutation (par exemple des gènes $B^{2}$ de sujets drépanocytaires [3]), à une souris $B$ thalassémique et de créer ainsi un modèle murin d'hémoglobinopathie humaine qui, dans le cas de la drépanocytose, serait extrêmement utile pour tester l'efficacité thérapeutique de nombreux produits.

A.K.

1. Babinet C, Morello D. Animaux transgéniques : une voie nouvelle pour l'étude du développement. médecine/sciences $1986 ; 2$ : 253-9.

2. Costantini F, Chada K, Magram J. Correction of murine $B$-thalassemia by gene transfer into germ line. Science 1986 ; 233 : 1192-4. 3. Rosa J. Un modèle en recherche clinique la drépanocytose. médecine/ sciences $1986 ; 2$ 559-67.

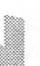
(1) 